\title{
Pemurnian Kondensat Hasil Pembuatan Gula Aren (Arenga pinnata) dengan Menggunakan Arang Aktif
}

\author{
Rosdiana Tidore ${ }^{a}$, Julius S. Pontoh a, Audy D. Wuntua \\ aJurusan Kimia, FMIPA, Unsrat, Manado
}

\section{KATA KUNCI}

Karbon Aktif

Kondensat

Nira Aren

\begin{tabular}{l}
\hline K E Y W O R D S \\
\hline Activated Charcoal \\
Condensate \\
palm sugar
\end{tabular}

\section{Pendahuluan}

Nira aren merupakan salah satu sumber bahan pangan dalam pembuatan gula. Secara tradisional, masyarakat mengolah nira aren menjadi gula batu (gula merah) atau gula semut yang berupa kristal (Baharuddin et al., 2007). Salah satu tahap penting dalam pembuatan gula aren tersebut adalah pemanasan untuk menguapkan airnya sehingga gula menjadi terkonsentrasi. Pada pembuatan gula tradisional, hal ini dilakukan dengan cara sederhana yaitu dengan cara memanaskan nira hingga mendidih. Pendidihan akan menyebabkan air menguap ke udara sehingga akan terbentuk larutan sirup kental.

\begin{tabular}{l} 
A B S T R A K \\
Penelitian ini bertujuan untuk memproses kondensat hasil \\
pengolahan gula aren melalui proses pemurnian dengan menggunakan \\
adsorben arang aktif dari tempurung kelapa, menganalisis komponen \\
kimia penyebab bau pada kondensat dengan teknik HPLC (High \\
Performance Liquid Chromatography) serta menganalisis daya serap \\
beberapa jenis arang aktif dari tempurung kelapa. Arang aktif yang \\
digunakan memiliki daya serap yang bervariasi, yaitu 37-45\%, 45-55\%, \\
$56-63 \%$ dan $70-85 \%$. Hasil penelitian menunjukkan bahwa arang aktif \\
dari tempurung kelapa dapat digunakan dalam proses pemurnian \\
kondensat dan berdasarkan hasil analisis HPLC (Hig Performance Liquid \\
Chromatography) terdapat tiga senyawa kimia yang menyebabkan bau \\
pada konsendat. Arang aktif yang memiliki kapasitas adsorpsi yang besar \\
yaitu arang aktif dengan daya serap $70-85 \%$ mampu menghilangkan bau \\
hingga volume kondensat 4.497mL/garang aktif. \\
\hline A B S T A C T \\
This research was aimed to purify the condensate produced during \\
sugar palm production using activated charcoal, to analyze the \\
compounds responsible to the odour of the condensate using high \\
performance liquid chromatography (HPLC) and to measure the adsorption \\
capacities of four types of activated coconut charcoals in absorbing the \\
condensate. The adsorption capacities of the activated charcoals were $37-$ \\
$45 \%$, $45-55 \%$, $56-63 \%$ and $70-85 \%$. The results showed that activated \\
coconut charcoal could be used to purify the condensate and there were \\
three compounds responsible to the odour of the condensate. The results \\
also showed that the activated carbon with the adsorption capacity of $70-$ \\
$85 \%$ was able to purify up to 4.497 mL condensate per gram charcoal. \\
\hline
\end{tabular}

Di Pabrik Gula Aren Masarang, Tomohon, Sulawesi Utara, penguapan air dari nira dilakukan dengan alat evaporator. Tiga proses penting yang terjadi di dalam Evaporator adalah pemanasan, penguapan dan pendinginan. Tujuan pendinginan adalah untuk mempercepat kondensasi uap air menjadi fase cair (air) sehingga penguapan akan berjalan dengan baik dan tidak terjadi kondensasi uap yang kemudian kembali kelarutan gula.

Sampai pada saat ini air hasil kondensasi pada pembuatan gula aren hanya digunakan pada sistem pendinginan peralatan pabrik. Padahal air hasil penguapan ini seharusnya dapat digunakan untuk keperluan manusia lainnya seperti sebagai air minum bahkan sebagai air suling untuk kebutuhan farmasi ataupun laboratorium.

*Corresponding author: Jurusan Kimia FMIPA UNSRAT, Jl. Kampus Unsrat, Manado, Indonesia 95115;Email address: tidore.rosdiana@yahoo.com Published by FMIPA UNSRAT (2012) 
Masalah yang dihadapi sekarang adalah air kondensasi tersebut mempunyai bau yang tidak enak dan belum ada informasi tentang senyawa penyebab bau pada kondensat tersebut. Pengetahuan tentang senyawa-senyawa bau ini akan memudahkan untuk menentukan proses yang tepat dalam pengolahan kondensat untuk menghilangkan bau.

\section{Tabel 1 - pH awal dari kondensatdan $\mathrm{pH}$ akhir dari Kondensat}

\begin{tabular}{|c|c|c|c|c|c|c|c|c|}
\hline \multirow{2}{*}{$\begin{array}{c}\text { Grade arang } \\
\text { aktif }\end{array}$} & \multicolumn{2}{|c|}{$\mathrm{pH}$ awal } & \multirow{2}{*}{ Rata-rata } & \multirow{2}{*}{$\begin{array}{c}\text { Standar } \\
\text { Deviasi }\end{array}$} & \multicolumn{2}{|c|}{$\mathrm{pH}$ akhir } & \multirow{2}{*}{ Rata-rata } & $\begin{array}{c}\text { Standar } \\
\text { Deviasi }\end{array}$ \\
\cline { 2 - 3 } & 1 & 2 & & & 2 & & \\
\hline $37-45 \%$ & 6,57 & 6,22 & 6,39 & 0,142 & 6,80 & 6,31 & 6,55 & 0,200 \\
\hline $45-55 \%$ & 7,07 & 7,34 & 7,06 & 0,004 & 7,34 & 7,26 & 7,30 & 0,032 \\
\hline $56-63 \%$ & 7,11 & 7,84 & 7,45 & 0,298 & 7,74 & 8,06 & 7,90 & 0,130 \\
\hline $70-85 \%$ & 6,74 & 6,31 & 6,52 & 0,17 & 6,76 & 6,80 & 6,78 & 0,016 \\
\hline
\end{tabular}

Tabel 2 - Volume kondensat sampai arang aktif menjadi jenuh

\begin{tabular}{|c|c|c|c|c|c|c|}
\hline \multirow{2}{*}{$\begin{array}{c}\text { Grade } \\
\text { arang aktif }\end{array}$} & \multirow{2}{*}{$\begin{array}{c}\text { Berat } \\
\text { arang } \\
\text { aktif (g) }\end{array}$} & \multicolumn{2}{|c|}{ Volume Kondensat (mL) } & \multicolumn{2}{|c|}{$\begin{array}{c}\text { Volume Kondensat per gram } \\
\text { arang aktif }\end{array}$} & \multirow{2}{*}{ Rata-rata } \\
\hline & & 1 & 2 & 1 & 2 & \\
\hline $37-45 \%$ & $6 g$ & $1.900 \mathrm{~mL}$ & $1.725 \mathrm{~mL}$ & $316 \mathrm{~mL}$ & $287 \mathrm{~mL}$ & $301 \mathrm{~mL}$ \\
\hline $45-55 \%$ & $3 g$ & $4.350 \mathrm{~mL}$ & $4.250 \mathrm{~mL}$ & $1.450 \mathrm{~mL}$ & $1.416 \mathrm{~mL}$ & $1.288 \mathrm{~mL}$ \\
\hline $56-63 \%$ & $1,5 \mathrm{~g}$ & $6.227 \mathrm{~mL}$ & $5.900 \mathrm{~mL}$ & $4.151 \mathrm{~mL}$ & $3.933 \mathrm{~mL}$ & $4.042 \mathrm{~mL}$ \\
\hline $70-85 \%$ & $1,5 \mathrm{~g}$ & $6.992 \mathrm{~mL}$ & $6.500 \mathrm{~mL}$ & $4.661 \mathrm{~mL}$ & $4.333 \mathrm{~mL}$ & $4.497 \mathrm{~mL}$ \\
\hline
\end{tabular}

Arang aktif kemudian dimasukkan ke dalam

\section{Metode}

\subsection{Alat}

Peralatan yang dilakukan dalam penelitian ini adalah gelas ukur, evaporator,buret, statif, gelas kimia, timbangan, oven, kolom yang berdiameter 2,5 $\mathrm{cm}$ dan panjang 9,7 $\mathrm{cm}$, pH meter, desikator dan HPLC.

\subsection{Bahan}

Sampel yang digunakan dalam penelitian ini adalah nira segar yang diperoleh dari petani di daerah Tomohon, Sulawesi Utara, dan arang aktif dari tempurung kelapa dengan 4 tingkat daya jerap (37-45 $\%$, 45-55 \%, 56-63 \%, dan 70-85 \%) yang diperoleh dari PT. Mapalus Makawanua Charcoral Industry, Bitung, Sulawesi Utara.

\subsection{Prosedur Penelitian}

\subsubsection{Pembuatan Kondensat}

Nira segar yang diperoleh dari petani Tomohon, dievaporasi dengan menggunakan destilator hingga diperoleh kondensat. Kemudian kondensat ditampung untuk digunakan dalam eksperimen pemurnian.

\subsubsection{Pemurnian Kondensat}

Arang Aktif sebelum digunakan, dimasukkan ke dalam oven pada suhu $105^{\circ} \mathrm{C}$ selama 1 jam, kemudian didinginkan dalam desikator selama 30 menit. kolom yang berdiameter $1,5 \mathrm{~cm}$. Sebelum kondensat dilewatkan pada kolom, terlebih dahulu diukur $\mathrm{pH}$ awalnya. Selanjutnya kondensat dilewatkan melalui kolom yang berisi arang aktif tersebut sampai arang aktif menjadi jenuh.Penentuan kejenuhan arang aktif dilakukan dengan memeriksa filtrat, yaitu dengan cara mencium bila filtrat. Jika fitrat mulai berbau berarti arang aktif telah jenuh. Arang aktif yang telah jenuh,diganti dengan arang yang baru sampai filtrat tidak berbau lagi.Hasil filtrat kemudian di tampung dalam gelas kimia, untuk dilihat berapa banyak volume kondensat yang terjerap setelah arang aktif menjadi jenuh. Setelah arang menjadi jenuh, $\mathrm{pH}$ kondensatnya di ukur lagi sebagai pH akhir.

Kondensat sebelum dan sesudah dilewatkan dalam kolom yang merupakan gabungan dari satu filtrat yang sama untuk semua daya jerap arang aktif (sampel komposit) dianalisis di Laboratorium Terpadu IPB, Bogor dengan menggunakan teknik HPLC.

\section{Hasil dan Pembahasan}

\subsection{Pengaruh Adsorpsi Terhadap pH Kondensat.}

Pengaruh adsorpsi arang aktif terhadap $\mathrm{pH}$ kondensat dapat dilihat dalam Tabel 1.

Berdasarkan Tabel 1 terlihat bahwa ada kecendrungan naiknya $\mathrm{pH}$ kondensat setelah dilewatkan melalui arang aktif untuk semua jenis arang. pH kondensat ditentukan oleh adanya zat-zat 
yang terlarut dalam kondensat. Naiknya $\mathrm{pH}$ kondensat dapat disebabkan oleh berkurangnya jumlah zat terlarut yang bertanggung jawab terhadap rendahnya $\mathrm{pH}$ kondensat selama proses adsorpsi menggunakan arang aktif.

Arang aktif dikenal memiliki kemampuan mengadsorpsi zat terlarut terutama zat-zat organik karena adanyagugus-gugus aktif pada permukaan arang aktif seperti karboksilat dan hidroksil. Kenaikan $\mathrm{pH}$ mengindikasikan bahwa senyawa yang teradsorpsi adalah senyawa asam. Hal ini bertentangan dengan gugus aktif pada arang aktif yang pada umumnya bersifat asam, sehingga diasumsikan bahwa senyawasenyawa penyebab bau yang bersifat asam ini teradsorpsi pada bagian-bagian hidroksil dari arang aktif.

\subsection{Daya jerap Arang aktif}

Daya jerap arang aktif dapat dilihat dalam Tabel 2.

Tabel 2 menunjukkan bahwa makin besar daya jerap arang aktif, maka makin besar volume kondensat yang dapat dilewatkan pada arang aktif sebelum arang aktif menjadi jenuh. Artinya 1 gram arang aktif mampu mengadsorpsi zat terlarut dalam sejumlah volume tertentu kondensat sebelum menjadi jenuh. Ketika arang sudah menjadi jenuh, maka arang tersebut harus diganti dengan arang yang baru karena akan berpengaruh dengan hasil filtratnya. Menurut Nugroho (2008) apabila seluruh permukaan arang aktif sudah jenuh, atau sudah tidak mampu lagi menyerap maka kualitas air yang disaring sudah tidak baik lagi, sehingga arang aktif harus diganti dengan arang aktif yang baru. Dari data yang ada terlihat bahwa yang paling besar daya jerapnya adalah jenis arang $70-85 \%$ yang mampu mengadsorpsi zat terlarut dalam kondensat sampai pada volume kondensat $4.497 \mathrm{~mL}$ untuk setiap gramnya.

Arang aktif dengan daya jerap yang tinggi memiliki luas permukaan yang lebih besar, sehingga memiliki situs adsorpsi yang lebih banyak dan selanjutnya memiliki kemampuan adsoprsi yang lebih besar. Menurut Subadra (2005) semakin besar daya jerap maka semakin besar kemampuan dalam mengadsorpsi adsorbat atau zat terlarut. Dengan demikian arang aktif dari tempurung kelapa dapat dikatakan mampu mengadsorpsi bau dari kondensat nira aren.

\subsection{Analisis dengan menggunakan Kromatografi HPLC}

Hasil analisis komponen kimia yang menyebabkan bau pada kondensat dapat dilihat dalam kromatogram pada Gambar 1 dan 2.

Hasil analisis HPLC memperlihatkan adanya Empat komponen utama dengan waktu retensi masing masing 5,89, 6,49, 6,99 dan 7,91 menit. Senyawa dengan waktu retensi 6,49 dan 6,99 menit merupakan senyawa yang utama dengan luas puncak 36630 dan 45407 unit. Kedua senyawa ini berkurang setelah kondensat dilewatkan pada arang aktif (Gambar 2). Demikian juga dengan senyawa dengan waktu retensi 5,89 , sebagaimana terlihat dari luas puncak yang berkurang (Gambar 1 dan 2). Senyawa dengan waktu retensi 7,91 menit tidak berubah setelah dilewatkan pada arang aktif yang mennujukkan semua senyawa ini tidak sebagai senyawa penyebab bau pada kondensat. Dari hasil analisis ini dapat disimpulkan bahwa ada tiga senyawa yang dapat menyebabkan bau pada kondensat nira aren. Namun demikian, senyawasenyawa tersebut belum dapat diketahui dan perlu diidentifikasi lebih lanjut.

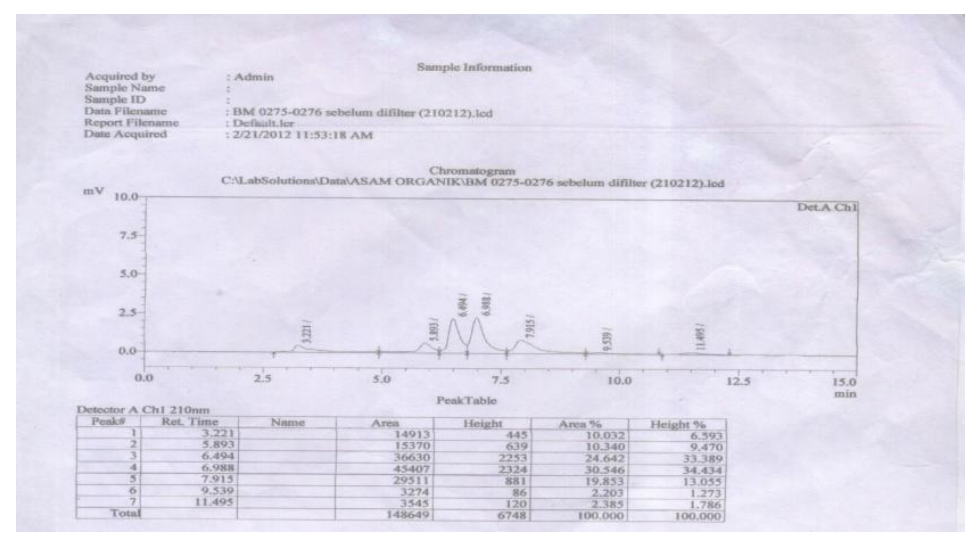

Gambar 1 - Kromatogram HPLC dari Kondensat sebelum dilewatkan pada arang aktif 


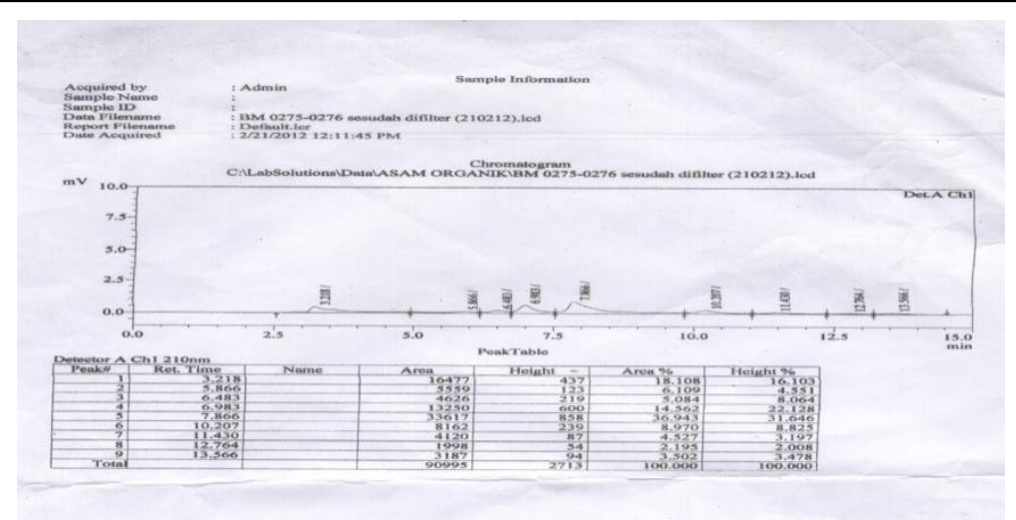

\section{Gambar 2. Kromatogram HPLC dari kondensat setelah dilewatkan pada arang aktif}

\section{Kesimpulan}

Berdasarkan hasil penelitian, dapat disimpulkan bahwa arang aktif dapat digunakan dalam proses pemurnian kondensat nira aren. Terdapat tiga komponen senyawa kimia utama yang menyebabkan bau pada kondensat nira aren, namun ketiga komponen senyawa kimia utama tersebut belum dapat diidentifikasi. Berdasarkan analisis terhadap beberapa daya jerap arang aktif, yang paling banyak mengadasorpsi kondensat adalah jenis arang aktif yang 70-8 \% karena mampu mengadsorpsi kondensat sampai volume $4.497 \mathrm{~mL} / \mathrm{g}$.

\section{Daftar Pustaka}

Baharuddin., M, Muin M., H, Bandaso. Pemanfaatan Nira Aren (Arenga pinnata Merr) Sebagai Bahan Pembuatan Gula Putih Kristal. Fakultas Kehutanan, Universitas Hasanuddin. 2007.

Nugroho. Penurunan Konsentrasi TSS pada Limbah Minyak Pelumas yang Berasal dari Bengkel dengan Menggunakan Reaktor Pemisah Minyak dan Karbon Aktif serta Zeoloit sebagai Absorben [Skripsi]. Universitas Islam Indonesia,Jogjakarta. 2008.

Subadra I., Bambang.,lqmal. 2005. Pembuatan karbon aktif dari tempurung kelapa dengan aktivator (NH4)HCO3 sebagai adsorben untuk pemurnian virgin coconut oil [skripsi]. Yogyakarta: Fakultas Matematika dan IImu Pengetahuan Alam, Universitas Gadjah Mada. 